framum

Sociológico

\section{Forum Sociológico}

Série II

$24 \mid 2014$

Circulação de saberes e desafios em saúde

\title{
A questão do "duplo/tríplice estatuto" nos estudos sobre gestão e organizações de saúde no Sistema Único de Saúde no Brasil
}

The "double/triple status" issue in studies about management and health organizations in the Brazilian National Health Care System

Luiz Carlos de Oliveira Cecilio

\section{OpenEdition}

Journals

Edição electrónica

URL: https://journals.openedition.org/sociologico/1125

DOI: $10.4000 /$ sociologico. 1125

ISSN: 2182-7427

Editora

CICS.NOVA - Centro Interdisciplinar de Ciências Sociais da Universidade Nova de Lisboa

Edição impressa

Paginação: 113-120

ISSN: 0872-8380

Refêrencia eletrónica

Luiz Carlos de Oliveira Cecilio, «A questão do "duplo/tríplice estatuto" nos estudos sobre gestão e organizações de saúde no Sistema Único de Saúde no Brasil », Forum Sociológico [Online], 24 | 2014, posto online no dia 01 novembro 2014, consultado o 31 março 2022. URL: http://

journals.openedition.org/sociologico/1125; DOI: https://doi.org/10.4000/sociologico.1125

Este documento foi criado de forma automática no dia 31 março 2022.

(c) CICS.NOVA 


\title{
A questão do "duplo/tríplice estatuto" nos estudos sobre gestão e organizações de saúde no Sistema Único de Saúde no Brasil ${ }^{1}$
}

\author{
The "double/triple status" issue in studies about management and health \\ organizations in the Brazilian National Health Care System
}

Luiz Carlos de Oliveira Cecilio

\section{De que lugar eu falo}

1 A reforma sanitária brasileira, que resultou no Sistema Único de Saúde (SUS) brasileiro, era, em sua origem, um movimento marcadamente do campo da esquerda, com forte base na academia, em particular nos seus departamentos de Medicina Preventiva e Social, organicamente articulado aos movimentos sociais que faziam oposição ao regime militar, notadamente nas décadas de 1970 e 1980. O Movimento Sanitário, tal como é normalmente designada esta singular articulação de um conjunto de forças políticas que irrompeu no cenário político brasileiro em plena ditadura (Scorel, 1999), tanto tomou a relação Estado e Sociedade como objeto de compreensão e crítica (Donnangelo e Pereira, 1976; Luz, 1979), como fez do próprio Estado território a ser disputado num projeto contra-hegemônico de forte inspiração gramsciana (Oliveira, 1988). Tal projeto logrou ampliar sua influência para outras forças políticas, constituir uma base parlamentar suprapartidária que, no contexto da constituição brasileira de 1988, conseguiu lançar as bases de um Sistema Nacional de Saúde, o SUS brasileiro (Brasil, 1990).

2 Formalmente criado em 1990, no contexto de um país redemocratizado, a tarefa posta agora para os militantes, intelectuais, ativistas da saúde era a construção do SUS: passar das grandes formulações, da reflexão crítica poderosa dos anos 70/80, das denúncias - 
ao modelo de atenção centrado no hospital, à medicina especializada e fragmentada, articulada com o complexo médico-industrial, aliada do capital no controle da força de trabalho, excludente de amplas parcelas da população - para a construção e operacionalização de um sistema de saúde público que no nosso ${ }^{2}$ projeto do Movimento Sanitário era universal, inclusivo, a ser construído no encontro com as necessidades de milhões de brasileiros que buscassem nele o cuidado de que precisassem.

Poucas vezes valorizamos essa torção ou deslocamento do Movimento Sanitário, de uma posição de crítica à posição de protagonista da construção, melhor dizendo, da invenção de um sistema de saúde, simultaneamente, à produção de conhecimento sobre ele. Este é o ponto de partida do texto.

4 As ideias que apresento aquisão localizadas em coordenadas tempo-espaciais bem delimitadas, e que, de partida, sinalizam a sua pretensão de alcance, pois representam as reflexões de um militante da reforma sanitária brasileira que viveu pessoalmente a "torção", a que me referi antes, do lugar da crítica externa nos anos 70/80 para o lugar do compromisso com a construção do SUS, produzindo-o por dentro, a partir dos anos 90, como profissional, gestor e investigador. Assim, falo a partir:

- do campo disciplinar denominado de Política, Planejamento e Gestão, que pertence ao campo multi e interdisciplinar mais amplo da Saúde Coletiva, portanto, que tem um modo muito particular de construir problemas teórico-práticos em função do objeto de que se ocupa (Paim e Almeida Filho, 1998).

6 - do momento atual de percepção, ainda difusa, do esgotamento do projeto inicial da reforma sanitária. Percepção não muito precisa, não muito bem enunciada, mas muito sentida por todos que militam na realização do SUS, e que nos tem posto o desafio de reformular elementos do projeto inicial.

7 - de estudos empíricos, de caráter qualitativo, conduzidos na ultima década, em parceria com gestores municipais do estado de São Paulo/Brasil que experimentaram avanços importantes na implantação do SUS. Pesquisas que tiveram financiamento público via um programa denominado PPSUS (Pesquisas em Políticas do Sistema Único de Saúde), um dos eixos da política do Ministério de Saúde para acompanhamento e avaliação do SUS. Pesquisas engajadas ou militantes, digamos assim. E que tem sido um dos principais dispositivos para a construção do grupo de pesquisa em política, planejamento e gestão em saúde, sob minha liderança na Universidade Federal de São Paulo.

8 - de achados da investigação da última pesquisa PPSUS, em dois municípios industrializados da região denominada $\mathrm{ABC}$ paulista, com importantes avanços no SUS, em parceria com o Instituto Universitário de Lisboa (ISCTE-IUL), e que vou utilizar, de modo livre, como um estudo de caso para ilustrar minhas reflexões.

\section{Três apontamentos para delimitar a discussão}

\section{Primeiro apontamento}

Com a construção do SUS os estudos qualitativos se impõem: o retorno do sujeito.

o SUS nasce como a principal produção da Saúde Coletiva brasileira, marcada, como disse antes, em seu nascedouro, por um pensamento altamente crítico, profundamente influenciado pelo marxismo estruturalista hegemônico nas décadas de 60 e 70 . A 
política de saúde do período é olhada como o objeto a ser recortado, analisado, explicado, denunciado. $O$ pensamento crítico é o sujeito que observa e denuncia o objeto desde fora. Com a criação do SUS, garantido o seu arcabouço legal pela lei orgânica da saúde de 1990, trata-se, agora, da desafiadora tarefa de construir um sistema de saúde em novas bases, de trabalhá-lo por dentro. Tarefa que, necessariamente será feita com seus atores reais: os governantes, os trabalhadores da saúde, os usuários. Tudo ali está para ser revisto, reconstruído, repensado. Se o pensamento crítico das décadas anteriores voltava sua atenção para as grandes determinações, para as grandes categorias como Estado, Sociedade Civil, Classes Sociais, tratava-se, agora, de lidar com os processos micropolíticos que vão ficando mais evidenciados ou são mais valorizados na tarefa de construção do novo sistema de saúde, em particular, o forte autogoverno dos trabalhadores e os vários sentidos dados por eles para o projeto SUS e para o trabalho em saúde (Cecilio e Mendes, 2004). Essa lida com o mundo real, ali onde se constrói o SUS, resultou tanto na formulação de novos problemas teórico-práticos, como, de modo progressivo, no deslocamento do foco das investigações e estudos realizados na academia para outro plano de análise, para outros referenciais teóricos, para outras categorias analíticas: teoria da ação, sentidos da ação, agir comunicativo, cultura, valores, entre outros. É quando progressivamente os estudos qualitativos vão se impondo como um caminho importante a ser explorado. É o que poderíamos chamar do "retorno do sujeito" nos estudos na saúde, movimento na Saúde Coletiva que acompanha tendência mais ampla nas ciências humanas, posterior à vaga estruturalista dos anos 60, 70 (Jodelet, 2009).

11 De qualquer forma, quis caracterizar, nesse primeiro apontamento, o deslocamento do interesse ou foco de atenção das grandes "estruturas", da grande política, para o cotidiano, para o mundo de trabalhadores produzindo o cuidado, disputando sentidos para seu trabalho, daí a relevância crescente dos estudos qualitativos na Saúde Coletiva. Vamos, então, para os outros apontamentos.

\section{Segundo apontamento}

12 A difícil compreensão e valorização da autonomia e dos autogovernos dos trabalhadores na produção das organizações de saúde: o trabalhador de saúde, esse estranho.

13 Como provocação, eu diria que o pensamento crítico presente na fundação da Saúde Coletiva se domestica e torna-se progressivamente conversador quando empenha-se na tarefa de (re)construção ou invenção das estruturas organizacionais do novo sistema de saúde. Tem havido a predominância de uma concepção funcionalizada/funcionalizante, quando se trata de pensar o trabalho em saúde, quando se trata de pensar o como fazer a gestão dos sistemas e dos serviços de saúde nessa tarefa de construção do SUS.

O conceito de "trabalhador moral" (Cecilio, 2007) sintetiza bem minhas críticas. Ele tem o sentido preciso de um trabalhador "moralmente" comprometido, aderido às propostas de gestão e modos de organizar a atenção propostos pelos formuladores e gestores do sistema de saúde (os especialistas), aos quais é esperada sua adesão irrestrita e acrítica. Tudo o que não se passa como o prescrito é visto como disfuncionalidade, explicada das mais variadas formas: conservadorismo político dos trabalhadores que não entendem as propostas; o corporativismo dos trabalhadores; o conservadorismo da universidade que só forma especialistas voltados para o mercado; a 
influência do complexo médico-hospitalar que logra moldar o imaginário de trabalhadores e usuários à sua imagem e semelhança, e por aí vai. Sem desconsiderar que tais explicações devem ser levadas em conta, e que têm peso real na explicação das dificuldades do SUS, o que tenho proposto é a abertura para uma compreensão mais íntima e sensível à micropolítica, buscando captar, ali, os sentidos do cuidado que vão sendo produzidos na realização do trabalho vivo (Merhy, 2002). Ou seja, as inesperadas singularidades produzidas no encontro trabalhador-usuário, os descuidados, mas também os bons cuidados realizados e que são invisíveis aos olhos do gestor. Não há avaliação feita pelos gestores, por mais finas ou menores que sejam suas malhas (usando a metáfora de uma rede de pescar), que consiga captar aquilo que fervilha na água, aquilo que é da ordem do contingente, da multiplicidade, do cotidiano, aquilo que compõe o mundo do trabalho, o mundo dos trabalhadores (Cecilio, 2011). Se, em boa medida, desde Fayol e Taylor, a teoria organizacional é uma teoria de gestão e, principalmente, para quem gerencia (Marsden e Townley, 2001: 34), podemos afirmar que, no caso do SUS, tem-se produzido estudos organizacionais a partir de uma perspectiva muito governamental, isso é, aquela dos gestores do sistema de saúde, atravessada, portanto, por forte normatividade, direcionalidade e prescritivismo, por mais generosas que sejam as intenções de seus formuladores. Tal fato, como não poderia deixar de ser, acaba tendo importante influência nas pesquisas, em particular pelo "duplo estatuto" que os pesquisadores na área da saúde assumem no atual contexto brasileiro, como veremos mais adiante. E esse é o ponto central do presente artigo.

\section{Terceiro apontamento}

15 A surpreendente criatividade dos usuários na produção de "sistemas de saúde": o usuário de saúde, esse estranho.

Se o olhar dos gestores e formuladores tem tido muita dificuldade de alcançar o horizonte micropolítico do mundo do trabalho em saúde, o "outro lado", tal dificuldade é ainda maior quando se trata de compreender os "usuários". Não que não se fale muito do usuário e da incontestável centralidade que ele deveria ocupar na organização do sistema de saúde e dos processos de trabalho cotidiano. A centralidade do usuário é componente importante da matriz discursiva do Movimento Sanitário brasileiro. Chega a haver um desgaste ou saturação de tal recomendação em textos e documentos, tanto oficiais como acadêmicos. No entanto, a presença ou a influência dos usuários parece estar sempre subordinada e normalizada por um conjunto de preceitos e recomendações que almejam produzir, por analogia com o trabalhador moral, um usuário moral da saúde. Usuário moral seria aquele moralmente comprometido a agir de acordo com parâmetros e critérios bem estabelecidos pelos especialistas gestores, pelos especialistas profissionais, caracterizado por:

- um modo de viver e de cuidar de si normalizado pela biomedicina e suas prescrições, com a supervalorização das medidas individuais de promoção e prevenção (Ayres, 2008);

18 - um modo de acessar e consumir serviços de saúde regulados pela lógica governamental; 
19 - um modo ou possibilidade de interferir na gestão dos serviços apenas nos espaços formais de controle social instituídos pelos governantes e regulamentados em legislação específica, por mais que se reconheça sua configuração generosa e inclusiva. De novo, tudo o que escapa a tal enquadramento normativo e regulador, da ordem de um biopoder sem dúvida, é disfuncional. O usuário moral é um ser abstrato, que se deseja ver movendo apenas dentro dos quadrantes estabelecidos pela política oficial.

21 Com estes três apontamentos, tentei delinear que campo de investigações antevejo na área de Política, Planejamento e Gestão em Saúde (PGGS), pertencente ao grande campo interdisciplinar da Saúde Coletiva nos próximos anos: serão investigações prioritariamente de caráter qualitativo, e as categorias trabalhador moral (ou o trabalhador funcionalizado) e o usuário moral (ou usuário disciplinado/normalizado) poderão ajudar a sinalizar a linha a ser cruzada, o outro lado a ser visitado. Pois, por tudo o que disse até agora, o desafio epistemológico do campo é exatamente este: visitar o outro lado!

\section{Considerações sobre o duplo estatuto pesquisador da saúde/profissional de saúde ou pesquisador da saúde/gestor da saúde}

A experiência brasileira de construção do SUS tem uma singularidade que penso ainda está por ser melhor estudada, em particular na área denominadade política, planejamento e gestão. E que singularidade é essa? Ela é definida por um conjunto expressivo de formuladores da política, de gestores ou gerentes do SUS em seus vários níveis e de profissionais de saúde das mais variadas formações que atuam no SUS e que vivem os efeitos das políticas oficiais nos seus cotidianos, e se dirigem à academia exatamente para estudar a política que eles mesmos formulam e da qual fazem a gestão, a política que, em boa medida, busca normalizar suas práticas profissionais.

São militantes, gestores, profissionais de saúde, especialistas da área de saúde, todosnós que temos nos dedicado a pesquisas na Saúde Coletiva, procurando, de alguma forma, avaliar o que temos feito, os avanços que têm sido possíveis, os impactos das políticas que não cessamos de formular, as transformações no cuidado a partir dos modelos de gestão e tecnoassistenciais que não cessamos de desenhar e propor. Uma legião de pesquisadores que possuem ora o duplo estatuto pesquisador da saúde/gestor da saúde, ora pesquisador da saúde/profissional de saúde, ora um tríplice estatuto pesquisador/ gestor/profissional ${ }^{3}$.

24 Merhy (2004) já havia se aproximado desta discussão com o conceito de saber militante do sujeito implicado para se referir aqueles que "procuram submeter a processos investigativos o seu próprio agir, trazendo, com isso, para a análise o seu próprio modo de dar sentido ao que é problema a ser investigado (...)" (p. 25). Para o autor, "o sujeito que ambiciona ser epistêmico está explicitamente subsumido na sua implicação, na sua forma desejante de apostar no agir no mundo de modo militante (...), a conformação do sujeito epistêmico está marcada pressupostamente pelo seu lugar como sujeito militante implicado" (25-26).

Penso que tal indicação de Merhy delineia novos contornos e traz novas questões para além do já clássico reconhecimento de que nas pesquisas qualitativas não há uma separação entre sujeito e objeto. Do mesmo modo, os conceitos de implicação e de análise 
de implicação como utilizados por Lourau (1975: 88-89) aportam elementos para uma melhor compreensão do conceito de duplo ou tríplice estatuto:

Estar implicado (realizar ou aceitar a análise de minhas próprias implicações) é, ao fim de tudo, admitir que eu sou objetivado por aquilo que pretendo objetivar: fenômenos, acontecimentos, grupos, ideias, etc. (...) O intelectual (...) com sua linguagem de sábio, com a manipulação ou o consumo ostensivo do discurso instituído e o jogo das interpretações múltiplas, dos "pontos de vista" e "níveis de análise", esconde-se atrás da cortina das mediações que se interpõem entre a realidade política e ele. (grifos atuais.)

Ainda para Lourau, e afirmando de modo direto e provocativo "Acabemos com os debates acadêmicos: digamos o que fazemos. Implicação: análise coletiva das condições da pesquisa" (Altoé 2003: 256-257). Voltarei a esse ponto mais à frente.

\section{E prosseguindo...}

Um mal-estar nos aflige: o SUS que vem sendo construído está muito longe do SUS que idealizamos, projetamos, imaginamos, desejamos. Para além das insuficiências de recursos financeiros para se garantir um sistema de saúde universal, fato que é real, há algo que nos escapa, algo que não se realiza, uma fugidia imagem que não se transforma em realidade, uma quimera que nos aturde. Penso que sem a assunção de alguma forma de análise de implicação nos estudos organizacionais pouco poderemos avançar na compreensão desses temas.

O desafio será experimentar os limites para a análise da implicação considerando-se a institucionalidade que os estudos sobre organizações e gestão em saúdevêm assumindo no Brasil. Institucionalidade entendida em duas dimensões principais. A primeira refere-se aos espaços formais a partir dos quais os estudos são realizados, centralmente, os departamentos de medicina preventiva e correlatos, submetidos a modos de financiamento, a regras acadêmicas, inseridos, portanto, no campo de poder, de normalização e disputa em que se transformou a pós-graduação e pesquisa em Política, Planejamento e Gestão em Saúde. A segunda dimensão da institucionalidade dos estudos organizacionais diz respeito às parcerias cada vez mais frequentes com os gestores do sistema de saúde para a realização de pesquisas, valorizadas e estimuladas pelo próprio Ministério da Saúde via PPSUS. Tais parcerias formais, por um lado, dão um sentido de engajamento da universidade na produção de um conhecimento comprometido com o aperfeiçoamento do SUS, por outro, frequentemente, adquirem caráter "avaliativo" para os gestores, os quais nem sempre se reconhecem nos resultados das pesquisas. A autoavaliação que fazem dos serviços e sistemas de saúde, e que resulta dos seus esforços de gestão, nem sempre parece ser contempladas pelos estudos feitos em parceria com a universidade. Nesse sentido, os estudos produzem um estranhamento nos gestores por vezes difícil de ser trabalhado. Tal estranhamento é um dispositivo central e dá uma boa dimensão da complexidade da análise de implicação.

Cabe então a pergunta: seria possível incorporar a análise da implicação nos estudos sobre gestão e organizações do Sistema Único de Saúde?

Sem pretender dar resposta para essa questão, vou apontar algumas reflexões sobre minha experiência recente como coordenador de pesquisa de caráter qualitativo conduzida na Universidade Federal de São Paulo em parceria com o ISCTE-IUL ${ }^{4}$. Considero a experiência, livremente, como um estudo de caso exploratório e 
exemplificador de algumas das ideias. Para além dos objetivos formais ou explícitos da pesquisa, destacarei possíveis elementos de análise de implicação no desenvolvimento da própria pesquisa.

31 O grupo de pesquisadores era bastante heterogêneo na sua composição, com vários estatutos de pesquisadores, mas todos, de um modo ou de outro, oriundos do campo de práticas do SUS, seja como gestores ou ex-gestores e profissionais de saúde, boa parte médicos, ou seja, o duplo/tríplice estatuto era uma característica marcante do grupo.

O objeto do estudo era a regulação em saúde. Na primeira fase da investigação, foram ouvidos os atores que sempre estão presentes em número expressivo de estudos da área de PPG, em particular aqueles que se ocupam da gestão, de novas formas de organização dos serviços de saúde e modos de implementação das diretrizes políticas do SUS: os gestores, os gerentes, os profissionais de saúde. Estes atores expressaram, através de entrevistas em profundidade, modos de pensar, de analisar o sistema de saúde que nos pareciam familiares, a nós, pesquisadores com duplo ou tríplice estatuto. De alguma forma, aqueles sujeitos da pesquisa falavam num código linguístico imediatamente apreensível por nós.

33 Na segunda fase, foram coletadas histórias de vida de pessoas muito utilizadoras dos serviços de saúde. Estas histórias de vida, transformadas em narrativas, tiveram o poder de conduzir nosso olhar e nossa escuta para surpreendentes dimensões, para modos de uso e composição dos vários serviços de saúde, que normalmente ficam fora do nosso olhar. E mais do que isso, obrigou-nos a entrar em um processo, ainda que tímido e exploratório, de autoanálise, ao perceber e vivenciar as tensões que atravessavam e constituíam o grupo composto por pesquisadores de duplo e tríplice estatuto.

Tínhamos que reconhecer que havia um "nós" que atravessava todos os momentos da pesquisa, desde o desenho geral do estudo (os seus pressupostos iniciais, a estrutura e condução das entrevistas, etc.), até o momento de análise do rico material que ia sendo produzido no campo. 0 coro de vozes que emergia das narrativas de vida nos impunha tomar como um problema ético e epistemológico um "nós" que, em boa medida, permanecia oculto até então. Um nós "naturalizado" em sua pretensão de objetividade e cientificidade. A presença de uma socióloga naquele grupo, de alguma forma uma "estranha no ninho", exerceu desde o início o papel de analisador, em particular ao produzir questionamentos em relação a escolhas que o grupo ia fazendo, como, por exemplo, a definição, a priori, de quais pessoas seriam incluídas no estudo, onde elas seriam recrutadas, tudo muito marcado por certas definições prévias, e que nos pareciam aproblemáticas, justamente por conta do nosso duplo/tríplice estatuto.

Momentos houve em que o duplo estatuto pesquisador/gestor resultava em conflito com o duplo estatuto pesquisador/profissional, pois, neste último caso, o pesquisador parecia trazer consigo de modo mais vivo uma vivência micropolítica fruto de sua atuação profissional, digamos assim. $\mathrm{E}$ aos poucos fui me dando conta, ainda que de forma não muita clara, de que a análise de implicação posta para o grupo era tão fundamental quanto o material que os usuários nos traziam com suas narrativas. 0 que estava em jogo era a possibilidade de colocar em análise, mesmo que de forma incipiente, a implicação do grupo com o objeto, em particular como o próprio grupo era atravessado e constituído por tensões que também atravessam e constituem o campo estudado.

Basta dizer que, em um momento já avançado na análise dos dados, uma pesquisadora do grupo que trabalha como médica também, ou seja, que traz muito marcado seu 
duplo estatuto profissional de saúde/pesquisadora de saúde, ao chamar de "maligna" a regulação governamental, provocou forte reação em um pesquisador que atua na regulação de um dos municípios estudados, portanto portador do duplo estatuto pesquisador-gestor. Foi um momento de grande tensão no grupo, que resultou no afastamento temporário do pesquisador-gestor dos seminários de pesquisa.

Os socioanalistas chamariam de analisador espontâneo esse inesperado mal-estar entre dois pesquisadores que vinham apresentando há meses uma convivência harmoniosa.

Outro exemplo: quando, já ao final do estudo, nos surpreendíamos e nos encantávamos com a criatividade das pessoas na composição de seus mapas de cuidados, de "seus" sistemas de saúde, um pesquisador comentou: o problema é que os usuários não veem o sistema de saúde como um todo, não veem um sistema de saúde articulado, mas apenas serviços isolados e fragmentados. Na verdade, havia quase uma queixa de que os usuários não veem o nosso sistema de saúde, não se comportam com a racionalidade pretendida por "nosso" sistema e por nós! E isso após meses de estudo, da cuidadosa e emocionada escuta de histórias de vida das pessoas. Foi o momento em que compreendi de forma mais aguçada quão complexa é a análise de implicação, em particular decalcar certas visões do mundo que portamos como uma segunda pele. Ocorreu-me a imagem de que a análise de implicação pode ser tão difícil, e tão dolorida, como um autoescalpelamento! Em Freire (1975), citado por Merhy (2004: 27), vamos encontrar ideia parecida ao afirmar que a cultura não pode ser externalizada ou arrancada do sujeito (coletivo ou individual) que é sempre um "sabido" por ser portador de saberes, isto porque a cultura lhe é constitutiva, como uma pele (...) Não é possível pensar o sujeito em ação sem sua implicação.

Por outro lado, as discussões dos achados feitas com os gestores dos dois municípios estudados foram surpreendentes. Em um deles houve recepção positiva, e os resultados da pesquisa funcionaram como provocação, trazendo indicações de possibilidades de mudança; no outro, os achados, que são verdadeiros deslocamentos em relação ao modo como os gestores pensam o sistema de saúde, foram escutados como críticas, inclusive trazendo o questionamento sobre o quanto a pesquisa teria trazido ou não alguma contribuição ou novidade para os gestores, inclusive a percepção de que a pesquisa parecia atender mais os interesses da universidade do que os da gestão, como explicitamente dito pela gestão local. Essa queixa aponta para a delicada relação entre universidade e serviços de saúde, em particular o quanto, historicamente, eles se sentem usados pela universidade, que mal faz uma "devolutiva" dos achados do estudo.

Como tentativa de sistematizar tais reflexões, aponto alguns elementos que estarão presentes ao nos propormos a realizar a análise de implicação nos estudos organizacionais.

41 - Um primeiro elemento diz respeito à análise do funcionamento interno de qualquer grupo que se dispõe a estudar o SUS, e que, na experiência brasileira recente, em geral são grupos "híbridos", se consideradas as diferentes vivências profissionais trazidas pelos vários pesquisadores, nos seus duplos ou tríplices estatutos, no nosso caso tão bem ilustrado pela tensão entre a médica/pesquisadora e o gestor/pesquisador. Somase a este aspecto as relações de poder que estarão presentes em qualquer grupo de pesquisa, para além dos diferenciais de ganhos financeiros - que sempre éum complicador, mas também o mais poderoso analisador destas relações (L'Abatte, 2005). Nos grupos de pesquisa há quase sempre uma hierarquia de poder/autoridade, fruto da divisão das tarefas, e que se revela de modo mais simbólico ou mais sutil, na forma de 
diferentes status de prestígio e reconhecimento, advindo, por exemplo, da maior ou menor proximidade com o líder do grupo, ou de um suposto lugar de tomadas de decisões cruciais para o grupo, que parece ficar meio nas sombras. É como seo grupo vivesse, paranoicamente, uma situação de heteronomia produzida em seu interior. É como se houvesse uns mais, uns menos, "amigos do rei". E, aqui, não se trata, de dizer se isso é verdade ou não, mas reconhecer que todo grupo vive, vive isso como real: fantasma(s) passa(m) a habitar o grupo (Vercauteren, Crabbé e Müller, 2010). Assim, o grupo vive seus fantasmas, que atuam como personagens reais: os anjos da antiprodução. Ou os buracos negros dentro do grupo. Talvez esse seja o mais difícil componente da análise de implicação, embora não seja o único, como veremos a seguir.

- $O$ outro elemento da análise de implicação nos estudos organizacionais diz respeito à nada fácil relação que deve ser construída entre o grupo de pesquisa - submetido à lógica e às exigências acadêmicas -, e os gestores, que quase sempre se veem como "objeto", portanto, observados e avaliados, e muitas vezes não reconhecidos nos seus esforços.

- Por fim, um último elemento, e quem sabe o mais central, diz respeito a como suportamos atravessar a linha e andar no "outro lado", reconhecendo o singular modo de o usuário ver o "sistema de saúde", ilustrado tão bem pela "queixa" do pesquisador em relação ao usuário que aparentemente não entende ou que não vê o "nosso" sistema de saúde, e sim serviços isolados e desarticulados.

Esta sistematização guarda semelhança com esquema proposto por Lourau ao indicar elementos que deverão ser contemplados na análise de implicação (apud Altoé, 2003: 255-256):
"Implicações primárias: 1. Implicações do pesquisador-praticante com seu objeto de pesquisa/intervenção; 2. implicações na instituição de pesquisa ou outra instituição de pertencimento e, antes de tudo, na equipe de pesquisa/intervenção; 3. Implicação na encomenda social e nas demandas sociais.
Implicações secundárias: 4. Implicações sociais, históricas, dos modelos utilizados (implicações epistemológicas); 5. Implicações na escritura ou qualquer outro meio que sirva de exposição da pesquisa."

Se posso sugerir que a incorporação da análise da implicação é fundamental para o avanço dos estudos qualitativos na área de PPG, imediatamente é possível reconhecer as dificuldades metodológicas presentes nesse tipo de proposta. Para Passos e Barros (2000),
"a noção de implicação, trabalhada pelos analistas institucionais, não se resume a uma questão de vontade, de decisão consciente do pesquisador. Ela inclui uma análise do sistema de lugares, o assinalamento do lugar que ocupa o pesquisador, daquele que ele busca ocupar e do que lhe é designado ocupar, enquanto especialista, com os riscos que isto implica. (grifos atuais.)

Parece-me que a composição multidisciplinar, como no caso da presença da socióloga, que além de não ter o duplo estatuto comum ao grupo era de outro país, pode funcionar como elemento importante na condução de tais estudos. Quem sabe um cuidado metodológico que poderemos ter, sempre, seria a incorporação de um estranho no ninho que funcione como analisador de nossas implicações, que nos faça interrogações ou um comentário tão analisador como quando a socióloga, em determinado momento, pergunta: "Mas de que "nós" se trata? Eu não sou parte dele..."

O fato é que, sem um pouco de disposição para a escuta, para o estranhamento, é impossível valorizar o que os usuários trazem de novidade, e, o que é central, corremos 
o risco de ficarmos prisioneiros de pressupostos que, afinal, apenas fazem confirmar tudo o que nós pensamos sobre como deve funcionar o "sistema" de saúde. O modo como eles produzem sentidos para a rede de cuidados primários, por exemplo, a partir de suas vivências, de suas carências, resulta em algo que poderia ser expresso assim, se os usuários pudessem se dirigir diretamente a nós pesquisadores/gestores/trabalhadores de saúde: a rede de cuidados primários que vocês estão construindo é boa para nós usuários, mas não é boa do modo como vocês pensam ou definem que ela deveria ser boa para nós. Nós retiramos dela, usamos nela, tudo o que ela pode oferecer de bom para nós, mas vocês não suportam ouvir isso de nós, e não conseguem aproveitar o que estamos dizendo para deixá-la ainda melhor para nós. Vocês não conseguem fazer disso um saber assessor (Cecilio et al, 2012).

Outro exemplo: a desenvoltura com que as pessoas escutadas compõem, articulam os planos privados de saúde com os serviços do SUS, fazem escolhas, julgamentos, buscam o bom médico, comparam, escolhem dentro de suas possibilidades, construindo, na prática, um sistema de saúde misto, coloca em julgamento a divisão bem marcada que nós, do movimento sanitário, gestores e trabalhadores de saúde sempre fizemos entre público (do "bem", porque segue a lógica de uma política pública, produz cidadania e direito) e privado (do "mal", porque segue a lógica do mercado e do lucro). Como, sem negar a luta por um sistema de saúde público universal, que tem sido a razão de ser das nossas lutas de tantos anos, confundindo-se com nossa vida profissional, nossa militância, como, sem desconsiderar isso tudo, conseguir escutar o que os usuários nos indicam sobre o modo como compõem "seus" sistemas de saúde em função de suas necessidades. E, mais do que isso, como incorporar estes saberes que vão sendo produzidos e, de modo solidário com os usuários, explorar novas possibilidades de composição do cuidado.

Para cruzar essa linha, para caminhar do outro lado, nosso duplo estatuto pesquisador da saúde/gestor da saúde precisa entrar em análise, submeter-se à constante análise de implicação. 0 que, convenhamos, não é tarefa fácil.

\section{BIBLIOGRAFIA}

ALTOÉ, S. (org.) (2004), René Lourau analista institucional em tempo integral, São Paulo, Hucitec.

AYRES, J. R. M. C. (2008), Sobre o risco: para compreender a epidemiologia, São Paulo, Hucitec.

BRASIL (1990), Lei 8.080 de 19 de setembro. Cria o Sistema Único de Saúde (SUS).

CECILIO, L. C. O. (2011), “Apontamentos teórico-conceituais sobre processos avaliativos considerando as múltiplas dimensões da gestão do cuidado em saúde”, Interface, Botucatu, v. 15, pp. 589-599.

CECILIO, L. C. O. (2007), “O trabalhador moral em saúde: reflexões sobre um conceito”, Interface, Comunicação Saúde e Educação, Botucatu, v. 11, pp. 345-363.

CECILIO, L. C. O. et al. (2012), “A Atenção Básica à Saúde e a construção das redes temáticas de saúde: qual pode ser o seu papel?”, Ciência e Saúde Coletiva, Rio de Janeiro, v. 17, pp. 2893-2902. 
CECILIO, L. C. O. e T. C. Mendes (2004), "Propostas alternativas de gestão e o protagonismo dos trabalhadores: por que as coisas nem sempre acontecem como os dirigentes desejam?", Saúde e Sociedade, São Paulo, v. 13, n.ำ 2, pp. 39-55.

DONNANGELO, M. C. e L. Pereira (1976), Saúde e sociedade, São Paulo, Duas Cidades.

JODELET, D. (2009), "O movimento de retorno ao sujeito e a abordagem das representações sociais”, Sociedade e Estado, Brasília, v. 24, n.ำ 3, pp. 679-712.

L’ABBATE, S. (2005), “Intervenção e Pesquisa Qualitativa em Análise Institucional”, in: N. F. Barros, J. G. Cecatti e E. R. Turato (orgs.), Pesquisa Qualitativa em Saúde: múltiplos olhares. Faculdade de Ciências Médicas/UNICAMP, Campinas-SP, pp. 235-246.

LOURAU, R. (1975), A Análise Institucional, Petrópolis/RJ, Vozes.

LUZ, M. T. (1979), As instituições médicas no Brasil: instituição e estratégia de hegemonia, Rio de Janeiro, Graal.

MARSDEN, R. e B. Townley (2001), “A coruja de Minerva: reflexões sobre a teoria na prática”, in S. R. Clegg, C. Hardy e W. N. Nord (orgs.), Handbook de estudos organizacionais: reflexões e novas direções, São Paulo, Atlas.

MERHY, E. E. (2002), Saúde: a cartografia do trabalho vivo, São Paulo, Hucitec.

MERHY, E. E. (2004), “O conhecer militante do sujeito implicado: o desafio de reconhecê-lo como saber válido”, in T. B. Franco, M. A. A. Peres, M. M. Foschiera e M. Pnizzi (orgs.), Acolher Chapecó: uma experiência de mudança do modelo assistencial com base no processo de trabalho, São Paulo, Hucitec.

OLIVEIRA, J. A. (1988), “Para uma teoria da reforma sanitária: democracia progressiva e políticas sociais", Saúde em Debate, Rio de Janeiro, n.ํ20, abril.

PAIM, J. S. e N. Almeida Filho (1998), "Saúde Coletiva: uma nova saúde pública ou campo aberto a novos paradigmas?", Revista de Saúde Pública, São Paulo, v. 32, n.ำ 4

PASSOS, E. e R. B. Barros (2000), “A construção do plano da clínica e o conceito de transdisciplinaridade”, Psic.: Teor. e Pesq. [online], vol. 16, n.ำ 1, pp. 71-79.

SCOREL, S. (1999), Reviravolta na saúde: origem e articulação do movimento sanitário, Rio de Janeiro, Editora Fiocruz.

VERCAUTEREN, D., O. Crabbé e T. Müller (2010), Micropolíticas de los grupos: para una ecología de las prácticas colectivas, Madrid, Traficantes de Sueños.

\section{NOTAS}

1. Comunicação apresentada no V Congresso Ibero-Americano de Pesquisa Qualitativa em Saúde - Circulação de Saberes e Desafios em Saúde, realizado em Lisboa entre 11 e 13 de Outubro de 2012.

2. Uso intencionalmente "nosso" projeto como indicação da minha inserção militante no Movimento Sanitário desde a sua constituição original na década de 1970, recusando, portanto, qualquer olhar de exterioridade em relação a ele. A importância desse posicionamento ficará mais clara no correr do texto.

3. O uso da primeira pessoa do plural neste parágrafo assume conotação especial na construção das reflexões que pretendo fazer no artigo. Tal uso pressupõe um "nós" que é exatamente o conjunto de atores que formulam a grande política e/ou se encarregam de fazer a gestão da sua 
operacionalização no cotidiano dos serviços de saúde. É, portanto, um “nós” posicionado, que, de alguma forma, mantém certa exterioridade em relação ao mundo micropolítico do cuidado, aqui referido às equipes de saúde que atuam diretamente na atenção.

4. "As múltiplas lógicas de construção de redes de cuidado no SUS: indo além da regulação governamental do acesso e utilização de serviços de saúde". Pesquisa financiada com recursos da Fundação de Amparo à Pesquisa de São Paulo (Fapesp) (2010-2012).

\section{RESUMOS}

O artigo problematiza o fato de que, no Brasil, um número crescente de profissionais de saúde e militantes da Reforma Sanitária dirige-se à academia para desenvolver estudos que tomam como objeto a política de saúde que eles próprios formulam e se ocupam em implementar. $O$ autor utiliza-se dos conceitos de duplo/tríplice estatuto para caracterizar tais pesquisadores que, ao estudarem as organizações e os processos de gestão em saúde, partem de pressupostos que eles não reconhecem como sendo marcados ou influenciados por suas inserções como trabalhadores ou militantes do SUS. São indicados três elementos para a análise de implicação nos estudos organizacionais: o reconhecimento das relações de poder e os "fantasmas" presentes em qualquer grupo de pesquisa; o esclarecimento das relações entre pesquisadores e trabalhadores de saúde "pesquisados"; a abertura dos pesquisadores para os saberes e práticas dos usuários que contrariam os pressupostos implícitos nos estudos organizacionais.

This paper considers the fact that an increasing number of Brazilian health professionals as well as Sanitary Reform militant people go to the university to develop studies concerned with the health policies that they themselves have formulated and implemented. The author uses the double/triple status concepts to characterize such researchers as they study organizations and health management processes and they do not recognize that their presuppositions are either marked or influenced by their working backgrounds and their engagement with SUS. Three elements are indicated for the implicative analysis in organizational studies: the recognition of power relations and the "ghosts" found in any research team; the relations between researchers and "investigated" health workers made clearer; the opening of researchers towards user-related knowledge and practices that are opposed to the implied presuppositions of organizational studies.

\section{ÍNDICE}

Keywords: implication analysis, researcher's double/triple statute, militant knowledge

Palavras-chave: análise de implicação, duplo/tríplice estatuto do pesquisador, saber militante

\section{AUTOR}

\section{LUIZ CARLOS DE OLIVEIRA CECILIO}

Universidade Federal de São Paulo. São Paulo/Brasil. Endereço para comunicação

(luizcecilio60@gmail.com) 